\title{
Lynch Syndrome - How can we improve the clinical awareness?
}

\section{Ralph Schneider ${ }^{1 *}$, Alois Fürst ${ }^{2}$ and Gabriela Möslein ${ }^{3}$}

${ }^{1}$ Department of Visceral, Thoracic and Vascular Surgery, Philipps University Marburg, Germany

${ }^{2}$ Department of Surgery; Caritas Hospital St. Josef, Regensburg, Germany

${ }^{3}$ Department of General and Visceral Surgery, Coloproctology, St. Josefs-Hospital, Bochum-Linden, Germany

Colorectal cancer (CRC) is one of the most frequent malignant diseases. About $3 \%$ of all patients with CRC will have Lynch syndrome, the most common hereditary CRC predisposing syndrome [1]. Patients with Lynch syndrome are at high risk for CRC and endometrium cancer but also have an increased risk for cancer of other extracolonic sites such as ovary, stomach, small bowel, hepatobiliary tract, pancreas, upper uro-epithelial tract, brain or skin [2]. Due to the diversity of cancer targets in this syndrome, physicians of nearly all medical disciplines must be aware of this predisposition. Since the former name of HNPCC (Hereditary Nonpolyposis Colorectal Cancer) was misleading, the syndrome has been renamed to Lynch Syndrome, acknowledging the role of Henry Lynch who decades ago described the main clinical features. The knowledge of epidemiologic, genetic and clinical characteristics of Lynch syndrome are important given that each index patient identified is the key to a family that would largely benefit from genetic counselling, DNA testing and screening [3-5].

The molecular genetic underlying mechanism in Lynch syndrome is a germline mutation in one of the mismatch-repair-genes (MSH2, MSH6, MLH1, PMS2 and MSH6) [2]. Typical for Lynch syndrome associated cancer is the early average age of onset of about 45 years as well as the characteristic target organs, especially syn- or metachronous cancers in one patient (e.g. endometrium and colorectal). For the large bowel the accelerated carcinogenesis of about 1-2 years must be accounted for in frequent and dedicated colonoscopies, removing all polyps. Furthermore, this high risk of synchronous and/or metachronous CRC must be discussed with the patients at the time of primary surgery, since $25-30 \%$ of patients will have surgery for a second primary CRC within 10 years of the first surgical resection [2]. New dated from a large multicenter international study shows that quality of live in patients that opt for extended colorectal resection at first colon cancer (subtotal colectomy) do not have a deteriorated quality of life. From the histopathological point of view the Lynch syndrome associated tumors are mostly poorly differentiated with an excess of mucoid and signet cell features, Crohn's like lesions as well as peritumoral and tumor-infiltrating lymphocytes [2].

Taking a nuclear pedigree in order to identify Lynch syndrome patients due to their positive family history should be obligatory for all CRC patients. The reduced penetrance of $85-90 \%$ may be misleading - therefore genetic counseling and generous recommendation to perform microsatellite instability (MSI) testing in the tumor specimen in suspected cases is warranted. Nevertheless, the cardinal features of Lynch syndrome mentioned above should be known and checked in every patient with CRC. Therefore, the acquisition of a comprehensive family history of cancer of all anatomic sites has to be an essential part of the clinical evaluation. These data have to be matched with the Amsterdam-I and -II-criteria as well as with the revised Bethesda criteria. If a patient fulfills the Amsterdam criteria, sequencing for mutation detection is justified and recommended. In order to save resources, MSI testing in tumor tissue of one affected family member is mainly helpful for identifying via immunohistochemistry which of the MSI genes is affected. A recently published study analyzing 12 families with 90 family members showed that $97.4 \%$ of the family members were informed about the diagnosis Lynch syndrome but only $29.5 \%$ of them had undergone a mutation analysis [6]. The authors could increase the number of moleculargenetic tested family members in the course of the study to $42.3 \%$ by information letters and phone calls [6]. These data show that a close contact between the attending physicians and the families - especially the relatives of the index patients - is required to provide professional information about Lynch syndrome and the possibilities and limitations of predictive genetic screening.

Patients with a proven germline mutation and high risk relatives are encouraged to participate in intensified screening programs - although recommendations differ between countries. The most important target for surveillance remains regular colonoscopic screening. Järvinen compared the incidence of CRC in two cohorts of at-risk members of 22 families with Lynch syndrome and found a 62\% CRC reduction in the colonoscopic screened group [7]. Five metachronous CRC were detected by Vasen 3.5 years following a negative colonoscopy [8]. An annual colonoscopic surveillance is recommended for individuals with Lynch Syndrome by Engel who analyzed 3474 colonoscopies in 1126 individuals in a prospective, multicenter cohort study [9]. $17 \%$ of CRC were detected through symptoms and only 2 of 43 CRC detected by follow-up colonoscopy were regionally advanced [9]. Moreover, tumor stages were significantly lower in CRC detected by follow-up colonoscopies compared with CRC detected by symptoms [9]. Therefore the colonoscopic screening has to start at an early age and has to be performed in frequent intervals. The extracolonic cancer screening should comprise endometrial aspiration and transvaginal ultrasound although we lack evidence-based data showing survival from such a screening $[2,10,11]$. Furthermore, a gastroscopy is recommend for all patients from the age of 35 independent from the existence of gastric cancer in the family history [12]. Here again, a close contact between the attending physician and the families with Lynch syndrome is required to encourage all family members to participate at the screening program. A recently published study showed that $90 \%$ of the index patients complied with the recommend screening examinations, in contrast to the number of family members which varied between $30-60 \%$ depending on the presence of cancer in their own history [6].

To evaluate a prophylactic colon surgery a prospective randomized trial comparing the common oncological resection with prophylactic colectomy was conducted 2004 in Germany. Unfortunately, the trial was cancelled due to a poor recruitment. However, the results of the before mentioned quality of life study should no negative effect of

${ }^{*}$ Corresponding author: Dr. Ralph Schneider, MD, Philipps University Marburg, Department of Visceral, Thoracic and Vascular Surgery,Baldingerstrasse, 35043 Marburg Germany, Tel: 0049-6421-5866441; Fax: 0049-6421-5868995; E-mail Ralph.Schneider@med.uni-marburg.de

Received September 03, 2011; Accepted November 04, 2011; Published November 08, 2011

Citation: Schneider R, Fürst A, Möslein G (2012) Lynch Syndrome - How can we improve the clinical awareness? Genetics 1:e101. doi:10.4172/21611041.1000e101

Copyright: (c) 2012 Schneider R, et al. This is an open-access article distributed under the terms of the Creative Commons Attribution License, which permits unrestricted use, distribution, and reproduction in any medium, provided the original author and source are credited. 
extended surgery. Taking this into account, clearly the decision for oncological or extended resection should be discussed with each patient - especially in the light of the high rate of metachronous colorectal cancers despite short interval screening. Generally merely prophylactic surgery is not recommended for Lynch syndrome patients without colorectal neoplasia. Henry Lynch proposes prophylactic surgery for patients with multiple polyps or at the time of first CRC. However, prophylactic hysterectomy and ovarectomy after family completion should be considered at the time of CRC diagnosis [13,15], and in women with a proven MSH6 mutation [13] since the endometrial cancer risk of $70 \%$ in this subset exceeds by far the risk for CRC (30\%).

To improve the knowledge and the clinical awareness for the Lynch syndrome training programs in the form of continuous medical education for physicians and lay awareness education for affected families must be intensified! Additionally, the information exchange between Lynch syndrome families via self-help groups should be encouraged. In order to achieve a higher participation rate for screening programs "Lynch syndrome passes" have been created and distributed. Most importantly however the awareness and the clinical features of this important and frequent predisposition should be known more broadly by physicians of many specialties, especially of surgeons, gastroenterologists, gynaecologists, urologists and dermatologists.

\section{References}

1. Hampel H, Frankel WL, Martin E, Arnold M, Khanduja K, et al. (2008) Feasibility of screening for Lynch syndrome among patients with colorectal cancer. J Clin Oncol 26: 5783-5788.

2. Lynch HT, Lynch PM, Lanspa SJ, Snyder CL, Lynch JF, et al. (2009) Review of the Lynch syndrome: history, molecular genetics, screening, differential diagnosis, and medicolegal ramifications. Clin Genet 76: 1-18.

3. Lynch HT, de la CA (1999) Genetic susceptibility to non-polyposis colorectal cancer. J Med Genet 36: 801-818.
4. Lynch HT, de la CA (2003) Hereditary colorectal cancer. N Engl J Med 348: 919-932.

5. Lynch HT, Boland CR, Gong G, Shaw TG, Lynch PM, et al. (2006) Phenotypic and genotypic heterogeneity in the Lynch syndrome: diagnostic, surveillance and management implications. Eur J Hum Genet 14: 390-402.

6. Schneider R, Rummele P, Dechant S, Hofstadter F, Lorenz W, et al. (2011) Familial non-polyposis colorectal carcinoma (Lynch syndrome) in Germany - analysis of information, advisory service and family screening. Dtsch Med Wochenschr 136: 17-22.

7. Jarvinen HJ, Aarnio M, Mustonen H, Collan KA, Aaltonen LA, et al. (2000) Controlled 15-year trial on screening for colorectal cancer in families with hereditary nonpolyposis colorectal cancer. Gastroenterology 118: 829-834.

8. Vasen HF, Nagengast FM, Khan PM (1995) Interval cancers in hereditary nonpolyposis colorectal cancer (Lynch syndrome). Lancet 345: 1183-1184.

9. Engel C, Rahner N, Schulmann K, Feder EH, Goecke TO, et al. (2010) Efficacy of annual colonoscopic surveillance in individuals with hereditary nonpolyposis colorectal cancer. Clin Gastroenterol Hepatol 8: 174-182.

10. Gerritzen LH, Hoogerbrugge N, Oei AL, Nagengast FM, Maaike APC van Ham, et al. (2009) Improvement of endometrial biopsy over transvaginal ultrasound alone for endometrial surveillance in women with Lynch syndrome. Fam Cancer 8: 391-397.

11. Lindor NM, Petersen GM , Hadley DW, Kinney AY, Miesfeldt S, et al. (2006) Recommendations for the care of individuals with an inherited predisposition to Lynch syndrome: a systematic review. JAMA 296: 1507-1517.

12. Holinski-Feder E, Morak M (2008) Hereditary nonpolyposis colorectal carcinoma: state of the art. Dtsch Med Wochenschr 133: 1690-1695.

13. Moslein G, Ohmann C, Wenzel M (2005) Prophylactic surgery for hereditary non-polyposis colorectal cancer. Chirurg 76: 1135-1144.

14. Burke W, Daly M, Garber J, Botkin J , Kahn MJE, et al. (1997) Recommendations for follow-up care of individuals with an inherited predisposition to cancer. I. Hereditary nonpolyposis colon cancer. Cancer Genetics Studies Consortium. JAMA 277: 919.

15. Mecklin JP, Jarvinen H (1993) Treatment and follow-up strategies in hereditary nonpolyposis colorectal carcinoma. Dis Colon Rectum 36: 927-929. 